\title{
INEFABILIDADE E SOCIALIZAÇÃO NA TRANSFERÊNCIA NO COMPARTILHAMENTO DE CONHECIMENTO TÁCITO EM PAÍSES MENOS DESENVOLVIDOS: O CASO DO CINE GROUP EM MOÇAMBIQUE
}

\section{Ineffability and socialization within the transfer of tacit knowledge to least developed economies: the case of Cine Group in Mozambique}

\section{Roberto Gonzalez Duarte}

Professor do Centro de Pós-graduação em Administração (CEPEAD). Universidade Federal de Minas Gerais. Belo Horizonte, MG. Brasil. e-mail:rgonzalezduarte@gmail.com

\section{José Márcio de Castro}

Professor do Programa de pós-graduação em Administração (PPGA) da Pontifícia Universidade Católica de Minas Gerais. Belo Horizonte, MG.Brasil.e-mail:josemarcio@pucminas.br

\section{Renata Simões Guimarães Borges}

Professora do Centro de Pós-graduação em Administração (CEPEAD) da Universidade Federal de Minas Gerais. Belo Horizonte, MG. Brasil. e-mail:renata.guimaraes.borges@gmail.com

* Os autores agradecem o apoio financeiro da Fundação de Amparo à Pesquisa de Minas Gerais (FAPEMIG) - APQ-02556-09.

\section{RESUMO}

O objetivo deste artigo é analisar os múltiplos papéis da socialização na transferência de conhecimento tácito entre uma empresa multinacional (EMN) brasileira e a sua subsidiária localizada em um país menos desenvolvido. A despeito dos avanços da literatura sobre transferência de conhecimento em EMNs e sobre o papel da socialização nesse processo, dois aspectos - um conceitual e outro empírico - têm sido negligenciados: (i) a inefabilidade do conhecimento tácito e (ii) a transferência de conhecimento para países menos desenvolvidos caracterizados por baixa capacidade absortiva. Realizou-se o estudo de caso do Cine Group, empresa brasileira do setor de audiovisual que, em 2009, instalou uma subsidiária em Maputo (Moçambique). Os resultados evidenciam que, em razão da inefabilidade do conhecimento tácito e do contexto de baixa capacidade absortiva da subsidiária, a socialização pode ter papéis distintos, que vão da transferência de conhecimento à mudança comportamental, passando pela aprendizagem conjunta.

Palavras-chave: transferência de conhecimento; socialização; capacidade absortiva.

\section{ABSTRACT}

The aim of this article is to analyze the multiple roles of socialization forwithin the iinteroorganizational transfer of tacit knowledge between a Brazilian multinational company (MNC) and its subsidiary located in a least developed country. In spite of advances of the literature on the transfer of knowledge within multinationals multinational companies (MNCs) and on the role of socialization in this process, two aspects - one theoretical, another empirical - have have bbeen neglected: (i) ineffability of tacit knowledge and (ii) transfer of knowledge to least developed countries with low absorptive capacity. We have carried out a case study about Cine Group, a Brazilian company in the media sector, which set up a subsidiary in Maputo (Mozambique) in 2009. Results have evidenced that due the ineffability of tacit knowledge and the context of low absorptive capacity of the subsidiary, socialization may have distinct roles, such as transfer of knowledge, conjoint learning, and behaviour change.

Keywords: knowledge transfer; socialization; absorptive capacity. 


\section{INTRODUÇÃO}

Se, por um lado, o conhecimento tácito é tido como o conhecimento mais valioso - está relacionado com o aprimoramento da qualidade dos produtos/serviços, a capacidade de inovação e a melhoria do desempenho organizacional (CHEN; EDGINGTON, 2005) -, por outro, é paradoxalmente o mais difícil de ser avaliado, formalizado e transferido (KOGUT; ZANDER, 1993; NONAKA, 1994; NONAKA; TAKEUCHI, 1995; ARVIDSSON, 2000). Tais especificidades têm dado lugar a uma série de pesquisas sobre, por exemplo, os fatores que afetam a sua transferência (FOOS; SCHUM; ROTHENBERG, 2006; JOIA; LEMOS, 2010; CASTRO; DINIZ; DUARTE; DRESSLER; CARVALHO., 2013), as barreiras à sua transferência (SZULANSKI, 1996; SZULANSKI; CAPPETTA; JENSEN, 2004; SZULANSKI; RINGOV; JENSEN, 2016) e os mecanismos mais adequados para se transferir conhecimento tácito intra e interorganizações (NONAKA; TAKEUCHI, 1995; LAWSON; PETERSEN; COUSINS; HANDFIELD, 2009). Como a transferência desse tipo de conhecimento depende, em grande parte, das características pessoais dos agentes envolvidos e dos vínculos existentes entre eles (confiança, atribuição de valor ao conhecimento, valores comuns, entre outros), mais do que de fatores organizacionais (JOIA; LEMOS, 2010), o papel da socialização na transferência do conhecimento tácito tem sido amplamente analisado investigado (FOOS et al., 2006; WANG, 2015).

Dois aspectos - um conceitual, outro empírico - relativos ao conhecimento tácito evidenciam facetas que não têm, contudo, recebido a mesma atençãosido negligenciadas. De um lado, o conceito de conhecimento tácito tradicionalmente utilizado por pesquisadores das áreas de negócios/gestão tem sido aquele proposto por Nonaka, Toyama e Byosière (2005) e Nonaka e Takeuchi (1995). Para esses autores, o conhecimento tácito (insights, intuições e suposições) é altamente pessoal e difícil de ser formalizado, posto que se encontra enraizado na ação, nos procedimentos, nas rotinas, nos ideais, valores e emoções (NONAKA; TAKEUCHI, 1995). Tsoukas
(2005) argumenta que essa interpretação do conhecimento tácito é, todavia, equivocada, pois ignora a sua inefabilidade, reduzindo-o a algo articulável. Esse tipo de conhecimento não pode, segundo o autor, ser capturado, traduzido ou convertido, mas apenas manifesto naquilo que o indivíduo faz. A práxis do indivíduo pode tão somente ser 'pontuada', como forma de se lhe chamar a atenção para aspectos não observados. A perspectivacrítica de Tsoukas (2005) tem uma implicação teórica importante: como a socialização, um dos principais mecanismos utilizados na transferência de conhecimento tácito, deve, então, ser compreendida?

Por outro lado, o resultado potencial da transferência de conhecimento decorrente dos fluxos de Investimento Estrangeiro Direto (IED) depende da natureza da economia de destino, especialmente, do nível de desenvolvimento do capital humano e da qualidade de sua infraestrutura e instituições (JONES, 2005), ou seja, da capacidade absortiva do país receptor desses investimentos (DUNNING; LUNDAN, 2008). A capacidade absortivae, por decorrênciasua vez resulta , a transferência de conhecimento depende, assim, dda disponibilidade de pessoas formalmente educadas e qualificadas (SLAUGTHER, 2004). Em outras palavras, quanto mais elevado o nível educacional da população na economia de destino, maior a probabilidade que os conhecimentos e ou tecnologias transferidos sejam absorvidos e utilizados para fins de inovaçãoinovação e criação de valor. O caso do Japão que “(...) demonstrou uma considerável capacidade absortiva à medida que buscava criar uma economia moderna a partir do século XIX" (JONES, 2005, p. 262) e, mais recentemente, da China (LIN, 2011) sugerem como uma elevada capacidade absortiva pode alavancar o crescimento econômico. Esse fenômeno, também, se repetiu, em maior ou menor grau, em vários países do antigo bloco soviético, tais como Hungria, República Tcheca, Polônia, Alemanha Oriental que maximizaram os benefícios da transferência de tecnologia, que dispunham de uma mão de obra altamente educada (VILLINGER, 1996). Nos últimos anos, observa-se um novo fenômeno: os países menos desenvolvidos têm atraído, em razão de suas altas taxas de crescimento (MCKINSEY, 2010), fluxos crescentes de IED (WIR, 2015). Diferentemente, contudo, dos países asiáticos e da Europa do Leste, 
Como eesses países têm sérios problemas sociais, como déficits educacionais substantivos e acentuada escassez de mão de obra qualificada (DUARTE; CASTRO; MIURA; MORAES, FEIJÓ; CARVALHO, 2014; MALIK, 2013). Entretanto, a, as implicações da baixa capacidade absortiva para a transferência de conhecimento tácito ainda não foram ainda examinadas.

Com a propósito de analisar os efeitos da inefabilidade e da baixa capacidade absortiva para a socialização na transferência internacional de conhecimento tácito e sua posterior recriação nas subsidiárias (MACHARZINA; OESTERLE; BRODEL, 2003), apresenta-se o caso do Cine Group, empresa brasileira do setor audiovisual que, em 2009, instalou uma subsidiária em Maputo (Moçambique). Os resultados evidenciam que, em uma primeira fase, a socialização tinha o papel de transferir conhecimentos técnicos da matriz brasileira para a subsidiária, isto é, compartilhar técnicas para a produção de conteúdo audiovisual. Em uma segunda fase, o propósito da socialização era criar, a partir de pressupostos conceituais definidos pela matriz e de referências visuais e culturais locais, conteúdo audiovisual local. Por fim, na última fase, o objetivo da socialização era a inovação, isto é, motivar os colaboradores da subsidiária a identificarem novos conceitos, incorporando-os aos produtos desenvolvidos. A inovação era necessária para assegurar não apenas a competitividade da subsidiária no mercado local, mas principalmente, sua autonomia em relação à matriz.

Para além desta seção, o artigo compreende outras cinco. Na próxima, discutem-se os pressupostos teóricos da transferência de conhecimento tácito. Subsequentemente, apresentam-se os procedimentos metodológicos e o caso do Cine Group, ressaltando-se os papéis da socialização para o compartilhamentoa traasnsferência do conhecimento e sua recriação no contexto moçambicano. Em seguida, discutem-se os principais desafios que a transferência de conhecimento tácito representa para as Empresas Multinacionais (EMNs) do setor de serviços que investem em países menos desenvolvidos e, finalmente, apresentam-se as considerações finais.

\section{PRESSUPOSTOS TEÓRICOS}

Uma das questões mais discutidas na literatura sobre transferência intra e interorganizacional do conhecimento é como e por que o tipo de conhecimento influencia o processo e o resultado da transferência (GHOSHAL; BARTLETT, 1988; KOGUT; ZANDER, 1992; ZANDER; KOGUT, 1995; HANSEN, 1999; ARGOTE; INGRAM, 2000; ARVIDSSON, 2000; GUPTA; GOVINDARAJAN, 2000; BECERRA; LUNNAN; HUEMER, 2008; DUNNING; LUNDAN, 2008; BRESMAN; BIRKINSHAW; NOBEL, 2010, 1999). O conhecimento tácito (insights, intuição e suposições), por exemplo, é altamente pessoal, enraizado na ação, procedimentos, rotinas, compromissos, ideais, valores e emoções e inclui tanto elementos técnicos (know-how informal, competências e habilidades) quanto cognitivos (modelos mentais mediante os quais os indivíduos interpretam o mundo) (NONAKA; TOYAMA; BYOSIĖRE, 2005 , p. 495). Visto que se baseia predominantemente em experiências que estão, por sua vez, ancoradas no contexto sociocultural no qual os indivíduos vivem e trabalham (BRESMAN; BIRKINSHAW; NOBEL, 2010; BECERRA; LUNNAN; HUEMER, 2008), o conhecimento tácito é de difícil codificação e formalização, logo a sua transferência é um processo moroso, custoso e incerto (KOGUT; ZANDER, 1992). Assim, paradoxalmente, se, por um lado é o conhecimento mais valioso, por outro, é o mais difícil de ser transferido (ARVIDSSON, 2000).

Embora amplamente utilizado na literatura, o conceito de conhecimento tácito tem sido, para alguns autores, interpretado de maneira equivocada (MOORADIAN, 2005; TSOUKAS, 2005). Ambos os autores sugerem um retorno às origens ou às raízes filosóficas do conceito, pois, segundo eles, alguns pressupostos apresentados por Polanyi foram, por razões distintas, ignorados. Em seu livro Tacit Dimension, Polanyi (1966:4) argumenta que 'nós podemos saber mais do que podemos expressar' (... 'we can know more than we can tell' - grifo do autor). Ressaltando o papel da percepção como uma instância do conhecimento tácito, Polanyi sugere que 'ao se elucidar a 
maneira pela qual os processos corpóreos participam em nossas percepções clarifica-se sobre as raízes corpóreas do pensamento, incluindo-se os maiores poderes criativos do homem' (POLANYI, 1966, p.15). Polanyi (1966) apresenta ao longo do livro diversos exemplos para ilustrar esse ponto. Se o pianista presta atenção ao movimento de seus dedos, por exemplo, ele pode paralisar o movimento, mas somente quando o pianista usa seus dedos e sua mente é que a música se produz. Portanto, o conhecimento tácito repousa sobre a nossa consciência das especificidades de uma entidade, mas quando se presta atenção a essas especificidades, perde-se de vista a entidade. Mooradian (2005), da mesma forma, argumenta que o conceito de Polanyi perdeu muito de sua precisão e de sua utilidade. Para esse autor, aAs concepções propostas por Nonaka (1994) e Nonaka e Takeuchi (1995) são excessivamente simplistas, pois tratam o conhecimento tácito como algo que tem valor em si mesmo.

Tsoukas (2005, p. 425) argumenta que “(...) a interpretação de Nonaka e Takeuchi do conhecimento tácito como 'conhecimento que ainda não foi articulado' - conhecimento esperando por sua 'tradução' ou 'conversão' em conhecimento explícito -, que tem sido adotada nos estudos de gestão, é equivocada, pois ignora a inefabilidade essencial do conhecimento tácito, reduzindo-o, então, a algo que pode ser articulado". Tsoukas (2005) refuta a ideia de que conhecimento tácito e explícito constituam as duas pontas de um continuum; para ele, são dois lados da mesma moeda. Retomando a definição de Polanyi, o autor argumenta que “(...) o conhecimento tácito consiste de um conjunto de elementos dos quais estamos subsidiariamente conscientes enquanto estamos focados em outra coisa" (movimentos do pianista e a música decorrente desses movimentos). Esse conhecimento contém um elemento inefável que se baseia em insights pessoais essencialmente inarticuláveis. Isso não significa que não se possa discutir sobre as atividades nas quais estamos envolvidos. Entretanto, “(...) em lugar de se insistir na conversão desse conhecimento, deve-se pensar em como chamamos a atenção uns dos outros para as coisas. Formas instrutivas de falar ajudam a nos reorientar sobre como nos relacionar uns com os outros e sobre o mundo que nos cerca, permitindo-nos falar e agir diferentemente" (TSOUKAS, 2005, p. 425). Assim, o “(...) conhecimento tácito não pode ser 'capturado', 'traduzido' ou 'convertido', mas somente demonstrado, manifesto naquilo que fazemos. Conhecimento novo não surge quando o tácito se torna explícito, mas quando nosso desempenho - nossa práxis - é pontuado de novas formas por meio da interação social" (TSOUKAS, 2005, p. 426).

Mooradian (2005), da mesma forma, argumenta que o conceito de Polanyi perdeu muito de sua precisão e de sua utilidade. Para esse autor, as concepções propostas por Nonaka (1994) e Nonaka e Takeuchi (1995) são excessivamente simplistas, pois tratam o conhecimento tácito como algo que tem valor em si mesmo. Para Mooradian (2005), a distinção entre conhecimento tácito e explícito é, na realidade, estrutural, referindo-se à relação entre o que se sabe (explícito) e aquilo sobre o qual esse conhecimento se baseia (implícito). O conhecimento explícito depende do conhecimento tácito, ou seja, para qualquer conhecimento explícito Ce há subjacente algum tipo de conhecimento tácito Ct. Essa concepção demanda, segundo Mooradian (2005), uma revisão do papel do conhecimento tácito na gestão do conhecimento. A transferência do conhecimento tem como alvo um conhecimento codificado, mas essa transferência é dificultada pelo conhecimento tácito que lhe é subjacente. Assim, o desafio para as organizações é identificar o conhecimento tácito relevante, de modo que o processo de transferência seja bem sucedido.

Para Nonaka, Toyama e Byosière (2005) a socialização pode ser entendida como o processo de se reunir conhecimentos tácitos mediante o compartilhamento de experiências. Entretanto, “(...) como o conhecimento tácito é específico de um contexto e difícil de ser formalizado, a chave para a sua aquisição é compartilhar a mesma experiência por meio de atividades conjuntas" (NONAKA; TOYAMA; BYOSIẼRE, 
2005, p. 495). Para os autores, a socialização pode ocorrer dentro da organização, quando “(...) aprendizes aprendem o seu trabalho, não por meio de palavras faladas ou de livros-textos, mas mediante a observação e imitação dos trabalhos de seus mestres e por meio da prática" (NONAKA et al., 2003, p. 495). E pode ocorrer externamente, quando há a interação entre os membros de uma organização e seus clientes e fornecedores. Essa concepção da socialização tem como pressupostos, primeiro, a distinção entre conhecimento explícito e conhecimento tácito; segundo, a conversibilidade entre eles; terceiro, a conversão é um processo social entre indivíduos; por fim, o conhecimento é criado a partir dessa interação social. Os pressupostos dessa concepção têm implicações para o entendimento acerca dos papéis da socialização para o compartilhamento e a recontextualização do conhecimento no contexto internacional.

Como argumentam Macharzina, Oesterle e Brodel (2003), o conhecimento baseia-se em interpretações individuais que são, por sua vez, determinadas socialmente. Assim, como o conhecimento é construído socialmente e a aprendizagem é sempre mediada por um processo social, o valor do conhecimento deriva, ao menos em parte, das convenções sociais, que diferem de um contexto social para outro. Para esses autores, “(...) as entidades sociais desenvolvem repertórios interpretativos (dois aspectos caracterizam esses repertórios: o que se sabe - conhecimento existente - e como se sabe - sistemas de sentidos) específicos que guiam suas interpretações. Esses domínios vinculam-se por meio da linguagem ou outras representações simbólicas. Se os respectivos padrões de linguagem das entidades sociais referem-se a diferentes sistemas de sentidos, o conhecimento deve ser recontextualizado para se ajustar ao repertório da unidade recipiente" (MACHARZINA et al., ; OESTERLE; BRODEL, 2003,2003, p. 636). A recontextualização pressupõe uma base de significados comuns, condição essencial para a comunicação de novas ideias (GUPTA; GOVINDARAJAN, 2000).

Ainda que a socialização seja um meio para a construção de significados comuns e para a recontextualização do conhecimento na unidade recipiente, o sucesso desta ação depende também do grau de desenvolvimento econômico do país ou, mais especificamente, da capacidade absortiva da unidade receptora (GUPTA; GOVINDARAJAN, 2000). A capacidade absortiva refere-se ao “(...) conjunto de rotinas e processos organizacionais mediante os quais as firmas adquirem, assimilam, transformam e exploram o conhecimento para produzir capacidade organizacional dinâmica" (ZAHRA; GEORGE, 2002, p. 186).

Pesquisas empíricas demonstram que o nível de capacidade absortiva do receptor influencia a transferência do conhecimento entre as unidades de uma EMN (MINBAEVA et al., 2003) bem como na apropriação do conhecimento tácito (LI; HSIEH, 2009; SCOTT; SARKER, 2010). Tanto a absorção como a difusão do conhecimento transferido pelas EMNs são negativamente afetadas quando os países de destino têem baixa capacidade absortiva (MEYER, 2004), como é o caso das economias menos desenvolvidas. Resultados de uma pesquisa recente sobre transferência de conhecimento em um país em desenvolvimento mostram, todavia, que a socialização ajuda a mitigar os efeitos negativos da baixa capacidade absortiva. $\mathrm{Na}$ investigação realizada por KHAN; SHENKAR; LEW Khan et al. (2015, p. 664) na indústria automotiva do Paquistão, os resultados mostram que as empresas estrangeiras usam mecanismos de socialização com o propósito explícito de transferirem conhecimento para os fornecedores locais. E, também, que existe uma relação positiva entre a capacidade absortiva do receptor e o uso de mecanismos formais (visitas técnicas, treinamento, desenvolvimento conjunto, entre outros) e informais (comitês técnicos, equipes, forças-tarefa, entre outros) no processo de transferência de conhecimento, E, por fim, que essa relação evidencia a importância da capacidade absortiva dos fornecedores para a exploração do conhecimento transferido mediante a socialização. Assim, segundo os autores, os mecanismos formais e informais podem ter papéis distintos nesse processo. Se, por um lado, os mecanismos formais facilitam a velocidade da transferência, por outro, os mecanismos informais facilitam a compreensão do conhecimento (Khan et al., 2015)KHAN; SHENKAR; LEW, 2015). 


\section{MÉTODO}

Tendo como objetivo de pesquisa a compreensão dos diferentes papéis da socialização no processo de transferência de conhecimento tácito entre matriz e subsidiárias de EMNs localizadas em países menos desenvolvidos, optou-se pelo estudo de caso de natureza qualitativa (EISENHARDT, 1989; YIN, 2015), que é mais adequado à investigação em uma ou poucas unidades e quando o propósito é analisar um fenômeno em profundidade (RIDDER, HOON; MCCANDELS, 2009; HALINEN; TÖRNROOS, 2005; EISENDARDT, 1989). Com a escolha do método do estudo de caso qualitativo foi possível identificar, descrever e analisar os diferentes papéis da socialização no processo de transferência de conhecimento tácito entre a matriz brasileira e a subsidiária moçambicana e, além disso, compreender como os colaboradores tanto do país de origem quanto do país de destino interagem, trocam e compartilham conhecimentos tácitos relevantes para o negócio da organização.

A partir dos objetivos da pesquisa, selecionou-se um caso de interesse teórico (EISENHARDT, 1989; EISENHARDT; GRAEBNER; SONENSHEIN, 2016) para o estudo da transferência de conhecimento tácito, considerando-se os múltiplos papéis da socialização no processo. Alguns critérios foram, ainda, determinantes para a seleção do caso. Primeiro, o nível de análise. PrimeiroA, a transferência de conhecimento dentro das unidades e os fluxos de conhecimento podem ser analisados em três níveis: nodal, diádico e sistêmico. No nível nodal, o foco da análise é o comportamento da unidade individual. No nível diádico, a análise recai sobre o comportamento das duas unidades e, por fim, no nível sistêmico, o foco é na rede como um todo (GUPTA; GOVINDARAJAN, 2000). Neste estudo, o foco é o nível nodal, isto é, o comportamento da subsidiária.

Segundo, o Cine Group abriu a sua primeira unidade no exterior, em Moçambique, em 2009, ou seja, sua a empresa já tinha uma boa experiência no mercado internacionaljá é desete anos, o que permite capturar insights relevantes sobre o processo de transferência de conhecimento ocorrido. Terceiro, segundo, trata-se uma empresa de porte médio, o que torna a escolha relevante, uma vez que a maior parte da literatura enfatiza organizações de grande porte e, na maioria das vezes, do setor industrial. Por fim, ainda é relativamente pelo reduzido o número de empresas brasileiras operando com subsidiárias em países menos desenvolvidos, o que sugere que o caso é de interesse para a compreensão do fenômeno da transferência de conhecimento, sobretudo no setor de serviços, nesse contexto específico.

Após a seleção do caso, passou-se à fase de planejamento da coleta da coleta de dados, com a elaboração do roteiro de entrevistas em profundidade (BAUER; GASKELL, 2003). O roteiro foi elaborado a partir da revisão da literatura e contemplou temas como transferência de conhecimento tácito, mecanismos de socialização, capacidade absortiva e assimilação de conhecimentos por parte dos colaboradores da subsidiária, os efeitos de culturas diferentes e da distância física sobre o processo de transferência e o compartilhamento de conhecimentos, entre outros aspectos. Realizaram-se seis entrevistas em profundidade (com a finalidade de se capturar novos elementos no curso de processo de trocas de conhecimento entre a matriz e a subsidiária, o diretor brasileiro da unidade moçambicana foi entrevistado em duas ocasiões) As outras entrevistas foram feitas com a diretora-presidente do Cine Group, três colaboradores técnicos - dois moçambicanos e um brasileiro - e uma colaboradora administrativa - brasileira. As entrevistas ocorreram na sede da empresa, em Brasília, e em Maputo. A coleta de dados ocorreu entre 2012 e 2014. Além das entrevistas, recolheram-se dados secundários de arquivos e documentos (YIN, 2015), entre os quais, do web site e matérias publicadas sobre o Cine Group.

Após a coleta de dados, transcreveram-se integralmente as entrevistas e começou-se o processo de pré-análise com a reunião das transcrições e os materiais secundários com vistas a uma primeira leitura exploratória dos dados (BARDIN, 2011). Em seguida, definiu-se algumas categorias, derivadas previamente da literatura, com vistas a organizar e interpretar os dados. A codificação e a análise subsequente dos dados consideraram as seguintes categorias: (i) capacidade absortiva da subsidiária; (ii) mecanismos e papéis da socialização; (iii) processo e resultados da transferência de conhecimento. 


\section{O CASO CINE GROUP}

\section{Fase 1 A entrada no mercado moçambicano: o desafio de compartilhar conhecimentos tácitos}

O Cine Group, com sede em Brasília e filais em São Paulo, no Rio de Janeiro e em Maputo (Moçambique), foi criado em 1997, com o objetivo de produzir documentários, vídeos institucionais, séries, mídias interativas, filmes publicitários e outros produtos de natureza audiovisual, tanto para a televisão aberta quanto para TV a cabo em diversos países. A empresa teve sua primeira experiência no mercado internacional ainda durante os anos 1990, quando participou de uma produção audiovisual na África do Sul. Mais tarde, em 2008, a partir de contatos estabelecidos em uma feira internacional de televisão (MIPCOM), o Cine Group decidiu abrir uma unidade em Moçambique, a primeira fora do Brasil. Inicialmente, a Cine Internacional, nome inicial da filial moçambicana, operava com brasileiros que foram expatriados para a unidade moçambicana, moçambicanos e outros brasileiros que se dividiam entre os escritórios dos dois países. Um dos primeiros projetos desenvolvidos em Moçambique foi a série de televisão, 'N'txuva - Vidas em Jogo', composta por 15 episódios de 15 minutos, e coproduzida com uma rede de televisão local. Ao longo do tempo, outros projetos foram desenvolvidos em outros países africanos.

Em qualquer canal de televisão - aberta e fechada - estão disponíveis os mais diversos tipos de produtos audiovisuais - séries, documentários, filmes, entre outros - produzidos em diferentes partes do mundo. Há, por um lado, produções, tais como documentários, que embora se ancorem em referências culturais do país em que são produzidas, caracterizam-se por uma linguagem mais universal, sendo distribuídas e consumidas mundo afora para telespectadores de diferentes contextos institucionais e culturais. E há, por outrolado, produções audiovisuais cujo conteúdo ancora-se nas referências culturais que são próprias de um determinado grupo cultural ou país. Somente quando se conhece ou se tem tais referências, pode-se contar uma história que suscite o interesse do público, fazendo com que este receba as informações e, ao mesmo tempo, sinta-se impactado por elas. O Cine Group produz tanto conteúdo do primeiro tipo, que é vendido para outros países, quanto do segundo tipo, isto é, produção de conteúdo visual destinado a um público específico.

Ambos combinam conhecimentos técnico e tácito. O primeiro refere-se às técnicas - da pré-produção à edição do conteúdo audiovisual - enquanto que o segundo (roteiro, imagens, edição, iluminação, entre outros), estreitamente vinculado ao primeiro, diz respeito aos aspectos da cultura visual de um dado grupo sociocultural (local, regional ou nacional). Quanto mais dirigida a um público específico, mais a produção audiovisual requer sensibilidade às particularidades institucionais sociais, culturais, políticas e econômicas desse grupo. A direção da empresa tinha ciência que para se produzir algo genuinamente moçambicano era preciso fazê-lo em colaboração com profissionais oriundos do país.

Embora consciente dessa necessidade, o Cine Group precisava superar um desafio: a escassez de mão de obra qualificada no setor audiovisual em Moçambique. Primeiro, em virtude da descolonização, o país perdeu conhecimento e know how e, posteriormente, em decorrência da subsequente guerra civil, Moçambique esteve relativamente isolado em relação ao acesso à informação e ao conhecimento, de uma maneira geral e, em particular, sobre a produção visual. Segundo, por causa do reduzido número de instituições formadoras de profissionais na área audiovisual, o número de pessoal qualificado disponível no mercado era baixo. Por fim, a escassez de programas de televisão e de produções cinematográficas limitava a constituição de um panorama mais diversificado de referências visuais locais. De acordo com o diretor da unidade moçambicana, “(...) muita gente ficou 'ilhada' em relação à recepção de informação de todo o mundo, até porque não existiam [ainda] tecnologias avançadas de comunicação como existem hoje". O sucesso da operação em Moçambique dependia, assim, da formação, da qualificação e do aperfeiçoamento dos profissionais locais. Assim, ainda no recrutamento, a empresa preocupou-se em selecionar profissionais locais, não apenas com interesse pela área de audiovisual, mas, sobretudo, com vontade de aprender. O diretor observa que, para se transferir qualquer conhecimento, é necessário, antes 
de qualquer coisa, que o receptor tenha real e genuíno interesse em aprender. Em suas palavras, “(...) ele [o candidato] também tem que ter uma coisa interior que o faça ter vontade de absorver".

Para formá-los e qualificá-los, era necessário compartilhar com esses profissionais o conhecimento, o know-how e as práticas do Cine Group. Isso dependia da integração social entre os profissionais brasileiros e moçambicanos; esta, por sua vez, estava condicionada à compreensão, por parte dos brasileiros, da cultura moçambicana. Sendo assim, a empresa buscou estimular a convivência entre os profissionais de ambos os países. O objetivo, segundo a presidente da empresa, era conhecer a cultura, conviver com os moçambicanos e se misturar com eles para compreender o seu modo de vida. Para ela, “(...) entender a cultura deles é viver com eles. O nosso primeiro ponto foi dizer aos nossos funcionários: saiam com os moçambicanos, entrosem". Ao longo da interação entre as partes, ficou claro, por exemplo, que a ausência de questionamentos ou sinais como o 'balançar a cabeça' poderiam sinalizar que determinados conteúdos não haviam sido, na realidade, efetivamente apreendidos, o que obrigou os profissionais brasileiros, segundo a presidente, a reveremem o "a maneira de ensinar".

Concretamente, essa revisão significou mais interação social entre brasileiros e moçambicanos. Uma brasileira, que trabalhava na produção, explica como isso ocorria no cotidiano da empresa: “(...) a presidente [do Cine Group] senta ali [junto com o profissional moçambicano] e diz: 'mostra lá tudo o que vocês produziram desde a última vez que eu vim'. Ela diz: ' (...) isso aqui está lindo, isso aqui está não está, o que aconteceu?' Aí, ele [profissional moçambicano] vai dizer o ponto de vista dele, eu vou dizer o meu ponto de vista. Tem uma autoanálise e tem também apoio (...)". Segundo o diretor (brasileiro) da unidade moçambicana: 'é um processo de construção, de amadurecimento, e de 'tentativa e erro' mesmo. Eu não tenho uma metodologia científica clara que defina: 'eu vou te dar um manual e este manual vai te ensinar a ter uma visão diferente.' É por isso que é preciso ter uma troca de vivências'. Na fase inicial, a socialização para a formação e qualificação dos colaboradores locais foi utilizada principalmente para os aspectos de caráter mais técnico, tais como pré-produção, captação (filmagem), edição e finalização, mas foi igualmente importante para a transferência de conhecimento de natureza mais tácita, tais como a luziluminação e a fotografia.

\section{Fase 2 A consolidação da subsidiária moçambicana: o desafio de se produzir conteúdo local}

Embora a transferência de conhecimentos e práticas (técnicos e tácitos) fosse uma prioridade, a socialização tinha outro propósito: desenvolver conteúdo visual "segundo" e "para" um contexto específico, ou seja, produzir algo que refletisse a realidade moçambicana. Em um país, que é um mosaico cultural, com múltiplas especificidades étnicas, linguísticas e religiosas, determinados elementos visuais podem fazer sentido em uma parte do país, mas não em outra; da mesma forma, o tempo para se 'contar uma história' pode ser bastante distinto daquele que seria utilizado em outras partes do mundo. Nas palavras do diretor, “(...) a gente já está conseguindo abordar os temas de uma maneira (...) que a comunidade perceba [esse] conteúdo". Esse foi, talvez, o principal desafio para o Cine Group, pois, se a aprendizagem dos elementos técnicos pode ser mais simples e ágil, a produção realização de conteúdo visual, por sua vez, é uma atividade bem mais complexa, que demanda uma socialização baseada no diálogo, na troca de conhecimento e, principalmente, na compreensão dos elementos simbólicos da cultura moçambicana. Essa compreensão da linguagem, dos aspectos simbólicos dependia não apenas da sensibilidade cultural, mas da imersão dos brasileiros na cultura moçambicana - essa imersão variou: enquanto alguns brasileiros viviam em Moçambique, outros passavam semanas no país ou, então, iam ao país com muita frequência, como era o caso da presidente do Cine Group.

Ainda que a sensibilização e a imersão contribuíssem para uma percepção mais acurada por parte dos brasileiros da cultura moçambicana, isso não substituía o 'olhar' de um moçambicano ou, nas palavras do diretor, “(...) somente quem está aqui vai poder ter a sensibilidade em dizer: 'olha, eu jamais colocaria aquela imagem ' $\mathrm{x}$ ' porque isso, dentro da cultura moçambicana, não funciona'”. Da mesma forma, a escolha equivocada, por exemplo, de uma 
cor (de uma capulana, por exemplo) - o significado das cores varia segundo as regiões - poderia invalidar um conteúdo audiovisual. Igualmente, o tempo para se contar uma história varia: poderia ser contada em outras partes do mundo em 15 minutos, mas, em Moçambique, pode demandar, por exemplo, $30 \mathrm{ou}$ 40 minutos. Segundo o diretor, “(...) as pessoas ainda não estão preparadas para ouvir em 15 minutos; elas estão preparadas para ouvir em 30 minutos. (...) então eu não posso impor um ritmo aqui porque as pessoas não estão preparadas". Assim, se o domínio das especificidades da linguagem, dos elementos simbólicos eram aspectos a serem apreendidos pelos brasileiros, por outro lado, para os moçambicanos, importava o domínio dos elementos técnicos (explícitos e tácitos), além de atitudes/comportamentos, tais como o comprometimento com o padrão de qualidade do Cine Group e a responsabilização quanto ao próprio papel no processo de trabalho.

\section{Fase 3 A autonomia da subsidiária moçambicana: a necessidade de inovação}

Seis anos após entrar em Moçambique, a operação do Cine Group já estava consolidada. Entretanto, nesse períodode tempo, o mercado audiovisual moçambicano adquirira novas feições, tornando-se mais dinâmico e competitivo. A economia moçambicana tem crescido significativamente nos últimos anos - em torno de $6 \%$ ao ano - o que tem contribuído para dinamizar rapidamente diferentes setores, inclusive os de serviços. O setor audiovisual, por exemplo, evoluiu muito, havendo atualmente produções bem mais sofisticadas no mercado.

Essa evolução obrigou o Cine Group a inovar, buscando diferenciais em suas produções audiovisuais - o que incluía novas abordagem dos temas, coletas de informações, desenvolvimento de novas linguagens visuais, de novos processos de edição, entre outros. O diretor dá um exemplo de como a emergência de novos parâmetros no mercado impactou o Cine Group. Após a empresa apresentar um produto para a televisão local, seu diretor diz: “(...) mas isso eu faço aqui dentro da minha casa. Eu os contratei porque vocês têm um diferencial de entregar [o produto] com uma edição diferente, uma edição com ritmo". Essa passagem mostra que se, por diferentes razões, o conhecimento existente no país esteve, durante um longo período de tempo, estagnado e o conhecimento do Cine Group era um diferencial, agora, com a dinamização do mercado e o surgimento de novos concorrentes, a inovação tornara-se um imperativo, demandando uma postura diferente dos profissionais moçambicanos do Cine Group. Para desenvolver essa nova postura, o Cine Group incentivou os colaboradores locais a buscarem novas referências audiovisuais, a desenvolverem um novo olhar, uma nova linguagem e também a serem mais autônomos. O diretor local da empresa corrobora esse ponto com o seguinte exemplo: “(...) o cameraman tem que olhar de tal maneira para uma situação e imaginar: 'bem, isso daqui eu posso captar de frente, posso captar de baixo, eu vou captar com uma aérea, vou captar com uma câmera $\mathrm{x}, \mathrm{y}$, z', porque ele já domina a técnica, mas, agora, ele tem que estar com o olho treinado pra saber de que forma que ele pode captar aquilo que me traga um resultado, uma linguagem interessante".

Ao buscar inovar, a empresa tinha também como objetivo modernizar a linguagem de seus produtos, mas também e reduzir a dependência em relação aos profissionais brasileiros. Com o avanço da tecnologia de telecomunicações, os colaboradores dos escritórios brasileiro e moçambicano podem se comunicar com muita frequência, mas a presença física dos profissionais brasileiros em Maputo era menos necessária, logo reduziu-se. Segundo o diretor, para desenvolverem essa nova postura, o caminho foi ser provocativo ou, em suas palavras, 'você tem que provocar e você tem que dar a mão'. Assim, além dos papéis convencionais (transferência unilateral de conhecimento e construção conjunta de conteúdo), a socialização adquiriu um cunho motivacional, cujo principal propósito era reduzir a dependência em relação ao escritório brasileiro e, mais importante, estimular uma postura de inovação constante nos profissionais locais. 
Atualmente, a subsidiária moçambicana do Cine Group conta com cerca de vinte colaboradores e produz diferentes conteúdos audiovisuais para uma ampla gama de clientes. Essa unidade já responde pela quase totalidade da demanda moçambicana. Eventualmente, a unidade brasileira apoia a subsidiária moçambicana. Segundo o diretor, “(...) existem trabalhos que nós não precisamos do Brasil (...), mas existem trabalhos que realmente precisamos deles, por exemplo, trabalhos que necessitam de computação gráfica”. A subsidiária moçambicana caracteriza-se pela combinação entre os conhecimentos brasileiro e moçambicano. Tal combinação trouxe benefícios inequívocos. Um foi a vantagem comparativa, pois, como ressalta o sócio da unidade moçambicana, “(...) o grande diferencial do Cine Group, por mais que ela atue localmente, [é] a gente trazer o brilho da criatividade de uma empresa brasileira". Outro foi a redução do custo de produção. A utilização de profissionais brasileiros tem um custo alto, o que diminuiria a vantagem comparativa da empresa no mercado local. Uma entrevistada brasileira observa a relação entre a utilização de profissionais moçambicanos, o custo e a competitividade: “(...) por ter uma equipe moçambicana qualificada, a gente já consegue competir melhor (...) imagina o custo que é trazer um diretor do Brasil - você tem que pagar passagem, hospedagem, comida! (...) Não é uma coisa para você competir com o resto do mercado; não é fácil, por mais que você tenha um padrão melhor de qualidade".

\section{DISCUSSÃO E CONCLUSÃO}

No caso da transferência internacional de conhecimento tácito, sua inefabilidade, por um lado, e a necessidade, por outro, de recontextualizá-lo na organização receptora indicam a relevância da socialização para a efetividade do processo. Na primeira fase, houve um a transferência de conhecimentos compartilhamento dos elementos técnicos, tais como pré-produção, produção, fotografia, iluminação e edição.produção, da produção audiovisual. Essa transferência e compartilhamento teve um caráter unilateral, isto é, da fonte (matriz) para o receptor (subsidiária). Além disso, como o conhecimento objeto da transferência - conteúdo audiovisual - ancora-se sobre pressupostos culturais, a socialização teve o propósito de se criar uma base de significados comuns, condição essencial para a comunicação de novas ideias (GUPTA; GOVINDARAJAN, 2000). Essabase de significados comunsfoi construída a partir de um foco bem definido:O lado brasileiro da operação tinha a responsabilidade de entender entender a cultura moçambicana e compreender o modo de vida dos moçambicanos. Se asocialização pressupõe, por um lado, convivência, interação entre as partes, por outro, no caso analisado, a responsabilidade de se criar 'significados comuns'assumia um caráter unilateral, isto é, a responsabilidade recaía sobre os colaboradores brasileiros. Os elementos técnicos e a base comum de significados constituíam os dois pilares sobre os quais se ergueram as etapas seguintes do processo de compartilhamento e construção do conhecimento da subsidiária moçambicana.

Na segunda fase, o propósito era criar conteúdo visual local, o que dependia da combinação entre o conhecimento técnico e o saber dos colaboradores locais. Nessa fase, teve lugar a aplicação do conhecimento adquirido anteriormente. Como argumentam Minbaeva et al. (2003, p. 587) “(...) a pura transmissão de conhecimento da fonte para o recipiente não tem nenhum valor se o receptor não utilizar esse conhecimento". O desenvolvimento de conteúdo audiovisual não se baseia somente na aplicação do conhecimento técnico, mas envolve aspectos mais tácitos, que, como sugerido por Tsoukas (2003), são pontuados, e não exatamente transferidos da fonte para a receptora. O exemplo da diretora-presidente que senta ao lado do colaborador e indaga do conteúdo produzido ilustra esse ponto. A socialização nessa fase teve, então, um caráter bilateral em que, de um lado, a subsidiária produzia conteúdo, levando em conta as referências visuais locais e, de outro, a matriz, por meio de seus colaboradores, pontuava a ação dos colaboradores locais, instruindo-os a desenvolverem um novo olhar. Os resultados dessa fase são a recontextualização do conhecimento da fonte na receptora (MARCHAZINA et al., 2003) e o desenvolvimento de conteúdo audiovisual local.

Finalmente, na terceira fase, os colaboradores locais já dominam os elementos técnicos e tácitos do 
conhecimento audiovisual e desenvolvem conteúdo apropriado à realidade local. O desafio era é inovar, assegurando a vantagem competitiva da subsidiária no mercado local, além ,de sua autonomia operacional e financeira, reduzindo ndosua a dependência da subsidiária em relação à matriz. , assegurando sua autonomiaoperacional e financeira, além de sua vantagem competitiva no mercado local. A socialização assume um novo propósitopapel: não é compartilhamento transferência de conhecimento técnico, nem desenvolvimento de conteúdo audiovisual, mas "provocar", "desenvolver uma nova postura", "buscar um nova linguagem". De novo, o sentido da socialização passa a ter um caráter mais unilateral, ou seja, o objetivo é, motivar e promover uma mudança comportamental dos colaboradores da subsidiária. O Quadro 1 sumariza como a socialização assume múltiplos papéis - compartilhamento, aprendizagem conjunta e motivação - ao longo do processo.

Quadro 1 Os diferentes papéis da socialização na transferência de conhecimento

\begin{tabular}{c|l|l|l|l}
\hline Fase & \multicolumn{1}{|c|}{ Tipo de conhecimento } & \multicolumn{1}{c|}{ Objetivo da socialização } & Direção & \multicolumn{1}{c}{ Papel da socialização } \\
\hline Fase 1 & $\begin{array}{l}\text { Pré-produção, produção audiovisual, } \\
\text { fotografia, } \\
\text { illuminação e edição. e produção } \\
\text { audiovisual. }\end{array}$ & $\begin{array}{l}\text { Compartilhamento Transferência } \\
\text { dos elementos técnicos da produ- } \\
\text { ção audiovisual. } \\
\text { Calonstrução de uma base de signi- } \\
\text { ficados comuns. }\end{array}$ & Unilateral. & $\begin{array}{l}\text { Transferência de conhecimento } \\
\text { técnicos. } \\
\text { Aprendizagem da cultura local. }\end{array}$ \\
\hline Fase 2 & Conteúdo audiovisual. & $\begin{array}{l}\text { Desenvolvimento de conteúdo } \\
\text { audiovisual local. }\end{array}$ & Bilateral. & Aprendizagem conjunta. \\
\hline Fase 3 & Novas referências audiovisuais. & Inovação do conteúdo audiovisual. & Unilateral. & $\begin{array}{l}\text { Motivacional } \\
\text { (mudança comportamental). }\end{array}$ \\
\hline
\end{tabular}

Fonte: Elaborado pelos autores.

Neste artigo discutiram-se os múltiplos papéis da socialização na transferência de conhecimento tácito entre matriz e subsidiária de EMNs instaladas em países menos desenvolvidos. As altas taxas de crescimento econômico de alguns desses países representam um atrativo, não apenas para as empresas que desejam expandir sua presença no mercado externo, mas também para aquelas que desejam iniciar sua internacionalização. Para a economia moçambicana, as EMNs constituem uma fonte de recursos, tais como conhecimento, tecnologia, know-how e práticas organizacionais, que podem eventualmente contribuir para alavancar o seu crescimento econômico (MEYER, 2004). Embora as EMNs possam ser canais para a transferência de conhecimento, a efetividade dessa transferência depende do tipo de conhecimento a ser transferido (PÉREZ-NORDTVEDT et al., 2008), dos mecanismos utilizados para a sua transferência, da capacidade absortiva da receptora e das barreiras à transferência. No caso dos mecanismos de interação social, os resultados da pesquisa de Khan et al. (2015) sugerem que os mecanismos formais e os informais têm papéis distintos no processo de transferência de conhecimento, influenciando a velocidade e a compreensão do conhecimento. Nesta pesquisa, demonstrou-se ademais que a socialização tem um caráter plástico, isto é, o objetivo, a direção e o papel podem variar ao longo do processo.

Este artigo traz uma contribuição teórica para a literatura sobre transferência de conhecimento tácito entre matriz e subsidiárias localizadas em contextos de baixa capacidade absortiva. Levando-se em conta as implicações da inefabilidade para a transferência do conhecimento tácito, sobretudo para a sua recontextualização em um contexto de baixa capacidade absortiva, argumenta-se que, além dos aspectos formal e informal da socialização, outros, tais como o seu objetivo, a sua direção e o seu papel, são determinantes para a efetividade da transferência do conhecimento tácito. Relativamente aos gestores envolvidos em processos de transferência de conhecimento, tendo em vista que a socialização é um mecanismo dinâmico, podendopode assumir múltiplos papéis, o ajuste da atuação gerencial, comportamental e temporalmente, é necessário a fim de garantir que o conhecimento seja compartilhado, 
aplicado e, mais importante, inovado. Em outras palavras, a socialização é um meio para se compartilhar conhecimento, mas é também um mecanismo para se recontextualizar um conhecimento existente e para se modificar comportamentos que resultem em desenvolvimento de novo conhecimento.

Como todo trabalho este tem limitações. Trata-se de um estudo de caso, logo as conclusões não podem ser generalizadas. A coleta de dados em países menos desenvolvidos pode ser especialmente difícil, mas, em que pesem as dificuldades para a obtenção de um maior volume de dados, os resultados jogam luz sobre questões teóricas importantes da transferência de conhecimento. Outra limitação diz respeito ao fato de se examinar um único setor. Tais limitações apontam, portanto, a necessidade de se examinar mais detalhadamente os papéis da socialização em outros países menos desenvolvidos (vale repetir: esses países têm recebido volumes crescentes de fluxos de IED, logo a questão da transferência de conhecimento merece ser estudada em um contexto pouco examinado do ponto de vista empírico) e, também, em outros setores, tais como os de infraestrutura e extrativista que são receptores importantes de investimentos estrangeiros.

\section{REFERÊNCIAS}

ARGOTE, L.; INGRAM, P. Knowledge transfer: a basis for competitive advantage in firms. Organizational behavior and human decision processes, v. $82, \mathrm{n} .1$, p. 150-169, 2000.

ARVIDSSON, N. Knowledge management in the multinational enterprise. In: BIRKINSHAW, J.; HAGSTRÖM, P. (Eds.). The flexible firm: capability management in network organizations. New York: Oxford University Press, p. 176-193, 2000.

BARDIN, L. Análise de conteúdo. 3 ed. Lisboa: Edições 70, 2011.

BAUER, M. W.; GASKELL, G. Pesquisa qualitativa com texto, imagem e som: um manual prático. Petrópolis: Vozes, 2003.
BECERRA, M.; LUNNAN, R.; HUEMER, L. Trustworthiness, risk, and the transfer of tacit and explicit knowledge between alliance partners. Journal of Management Studies, v. 45, n. 4, p. 691-713, 2008.

BRESMAN, H.; BIRKINSHAW, J.; NOBEL, R. Knowledge transfer in international acquisitions. Journal of International Business Studies, v. 30, n. 3, p. 439-462, 1999.

BRESMAN, H.; BIRKINSHAW, J.; NOBEL, R. Knowledge transfer in international acquisitions. Journal of International Business Studies, v. 41, n. 1, p. 5-20, 2010.

CASTRO, J. M. de et al. Fatores determinantes em processos de transferência de conhecimentos: um estudo de caso na Embrapa Milho e Sorgo e firmas licenciadas. Revista Brasileira de Administração Pública, v. 47, n. 5, p. 1283-1306, 2013.

CHEN, A. N. K; EDGINGTON, T. M. Assessing value in organizational knowledge creation: considerations for knowledge workers. MIS Quarterly, p. 279-309, 2005.

DUARTE, R.G. et al. FDI inflows, transfer of knowledge; and absorptive capacity: the case of Mozambique. African Journal of Business Management, v.8, n.1, p. 14-24, 2014.

DUNNING, J. H.; LUNDAN, S. M. Multinational enterprises and the global economy. Cheltenham: Edward Elgar Publishing, 2008.

EISENHARDT, K. M. Building theories from case study research. Academy of Management Review, v. 14, n. 4 , p. 532-550, 1989.

EISENHARDT, K. M.; GRAEBNER, M. E.; SONENSHEIN, S. Grand challenges and inductive methods: rigor without rigor mortis. Academy of Management Journal, v. 59, n. 4, p. 1113-1123, 2016. 
FOOS, T.; SCHUM, G.; ROTHENBERG, S. Tacit knowledge transfer and the knowledge disconnect. Journal of Knowledge Management, v. 10, n. 1, p. 6-18, 2006.

GHOSHAL, S.; BARTLETT, C. A. Creation, adoption and diffusion of innovations by subsidiaries of multinational corporations. Journal of International Business Studies, v. 19, n. 3, p. 365-388, 1988.

GUPTA, A. K.; GOVINDARAJAN, V. Knowledge flows within multinational corporations. Strategic Management Journal, p. 473-496, 2000.

HALINEN, A.; TÖRNROOS, J. Å. Using case methods in the study of contemporary business networks. Journal of Business Research, v. 58, n. 9, p. 1285-1297, 2005.

HANSEN, M. T. The search-transfer problem: the role of weak ties in sharing knowledge across organization subunits. Administrative Science Quarterly, v. 44, n. 1, p. 82-111, 1999.

JOIA, L. A.; LEMOS, B. Relevant factors for tacit knowledge transfer within organizations. Journal of Knowledge Management, v. 14, n. 3, p. 410-427, 2010.

JONES, G. Multinationals and global capitalism: from the nineteenth century to twenty-first century. Oxford: Oxford University Press, 2005.

KHAN, Z.; SHENKAR, O.; LEW, Y. K. Knowledge transfer from international joint ventures to local suppliers in a developing economy. Journal of International Business Studies, v. 46, n. 6, p. 656675, 2015.

KOGUT, B.; ZANDER, U. Knowledge of the firm, combinative capabilities, and the replication of technology. Organization Science, v. 3, n. 3, p. 383-397, 1992.

KOGUT, B.; ZANDER, U. Knowledge of the firm and the evolutionary theory of the multinational corporation. Journal of International Business Studies, v. 24, n. 4, p. 625-645, 1993.
LAWSON, B. et al. Knowledge sharing in interorganizational product development teams: the effect of formal and informal socialization mechanisms. Journal of Product Innovation Management, v. 26, n. 2, p. 156-172, 2009.

LI, C. Y.; HSIEH, C. T. The impact of knowledge stickiness on knowledge transfer implementation, internalization, and satisfaction for multinational corporations. International Journal of Information Management, v. 29, n. 6, p. 425-435, 2009.

LIN, J. Y. From flying geese to leading dragons: new opportunities and strategies for structural transformation in developing countries. Mozambique: WIDER Annual Lecture, 2011.

MACHARZINA, K.; OESTERLE, M. J.; BRODEL, D. Learning in multinationals. In: DIERKES, M. et al. Handbook of organizational learning \& knowledge. Oxford: Oxford University Press, p. 631-656, 2003.

MALIK, K. Human Development Report 2013. The rise of the south: human progress in a diverse world. ONU. 2013.

MCKINSEY GLOBAL INSTITUTE. Lion's on the move: the progress and potential of African economies. Disponível em: <http://www. mckinsey.com/ global-themes/middle-east-and-africa/lions-on-the-move>. Acesso em: 14 abr. 2016.

MEYER, K. E. Perspectives on multinational enterprises in emerging economies. Journal of International Business Studies, v. 35, n. 4, p. 259-276, 2004.

MINBAEVA, D. et al. MNC knowledge transfer, subsidiary absorptive capacity and HRM. Journal of International Business Studies, v. 34, n. 6, p. 586-599, 2003.

MOORADIAN, N. Tacit knowledge: philosophic roots and role in KM. Journal of Knowledge Management, v. 9, n. 6, p. 104-113, 2005. 
NONAKA, I. A dynamic theory of organizational knowledge creation. Organization Science, v. 5, n. 1, p. 14-37, 1994.

NONAKA, I.; TAKEUCHI, H. The knowledge-creating company: how Japanese companies create the dynamics of innovation. Oxford: Oxford University Press, 1995.

NONAKA, I.; TOYAMA, R.; BYOSIÈRE, R. A theory of organizational knowledge creation: understanding the dynamic process of creating knowledge. In: DIERKES, M. et al., Handbook of organizational learning \& knowledge. Oxford: Oxford University Press, p. 491-517, 2005.

PÉREZ-NORDTVEDT, L. et al. Effectiveness and effciency of cross-border knowledge transfer: an empirical examination. Journal of Management Studies, v. 45, n. 4, p. 714-744, 2008.

POLANYI, M. The tacit dimension. Garden City: Doubleday \& Company, 1966.

RIDDER, H. G.; HOON, C.; MCCANDLESS, A. The theoretical contribution of case study research to the field of strategy and management. Research Methodology in Strategy and Management. Emerald Group Publishing Limited, 2009. p. 137-175.

SCOTT, C. K.; SARKER, S. Examining the role of the communication channel interface and recipient characteristics on knowledge internalization: a pragmatist view. IEEE Transactions on Professional Communication, v. 53, n. 2, p. 116-131, 2010.

SZULANSKI, G. Exploring internal stickiness: impediments to the transfer of best practice within the firm. Strategic Management Journal, v. 17, p. 27-43, 1996.
SZULANSKI, G.; CAPPETTA, R.; JENSEN, R. J. When and how trustworthiness matters: knowledge transfer and the moderating effect of causal ambiguity. Organization Science, v. 15, n. 5, p. 600-613, 2004.

SZULANSKI, G.; RINGOV, D.; JENSEN, R. J. Overcoming stickiness: how the timing of knowledge transfer methods affects transfer difficulty. Organization Science, v. 27, n. 2, p. 304-322, 2016.

TSOUKAS, H. Do we really understand tacit knowledge? In: EASTERBY-SMITH, M.; Lyles, M. A. (Eds.). Handbook of organizational learning and knowledge management. Malden: Blackwell Publishing, p. $410-427,2005$.

VILLINGER, R. Post-acquisition managerial learning in Central East Europe. Organization Studies, v. 17, n. 2, p. 181-206, 1996.

WANG, K. T. Research design in counseling. Scarborough/ON: Nelson Education, 2015.

WORLD INVESTMENT REPORT. Reforming International Investment Governance. United Nations Conference on Trade and Development, 2015.

YIN, R. K. Estudo de caso: planejamento e métodos. Porto Alegre: Bookman Editora, 2015.

ZAHRA, S. A.; GEORGE, G. Absorptive capacity: a review, reconceptualization, and extension. Academy of Management Review, v. 27, n. 2, p. 185-203, 2002.

ZANDER, U.; KOGUT, B. Knowledge and the speed of the transfer and imitation of organizational capabilities: an empirical test. Organization Science, v. 6, n. 1, p. 76-92, 1995. 